\title{
CULTURAL AND PSYCHOSOCIAL INFLUENCES ON DISABILITY, AND AN INTERVENTION TO REDUCE LOW BACK PAIN AWIONG NURSES
}

\author{
By \\ Sudath Shirley Pathmasiri Warnakulasuriya
}

Thesiiss submiitteed to the Umiversity of Sri Jkayewardenepunat for the awand of the IDzegree off Drectior off PPlilbssophy on "CCuiltural and Psychosocial Influences on Disability, and an Intervention to Reduce Low Back Pain among Nurses", on 87th August2014 


\section{DECLARATION BY THE CANDIDATE}

The work describe in this thesis was carried out by me under the supervision of Prof. Roshini Peiris-John, Prof. S Sivayogan, Prof. Nalini Sathiakumar, Prof. A. R. Wickramasinghe, and a report on this has not been submitted to any university for the purpose of evaluation

2810412015

Date
W.S.S. Putho

Signature of the candidate

\section{CERTIFICATION OF THE SUPERVISORS}

We certify that the above statement made by the candidate is true and that this thesis is suitable for submission to the university for the purpose of evaluation

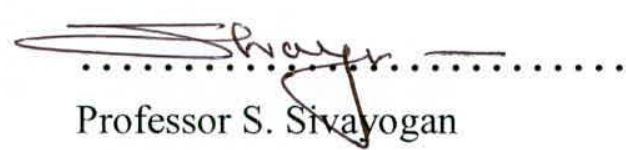

Nalini Sattiakumas

Profesor Nalini Sathiyakumar
Professor Roshini Peiris - John

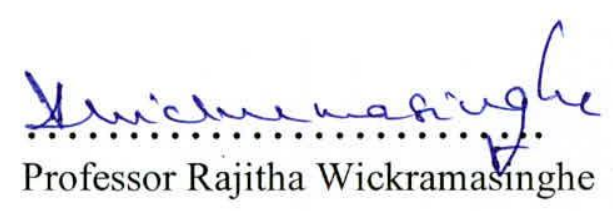




\section{CERTIFICATION OF THE SUPERVISORS}

We certify that the candidate has incorporated all corrections, additions and amendments recommended by the examiners

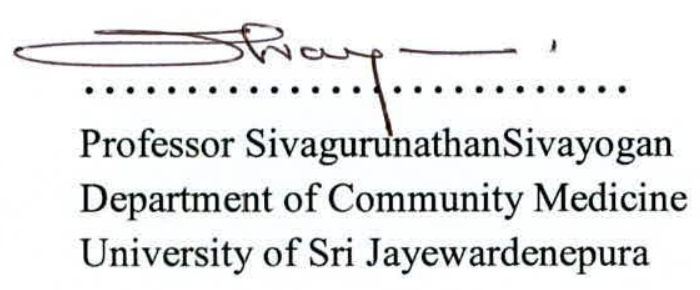

Nalini Saltiakemar

ProfesorNaliniSathiyakumar

School of Public Health

University of Alabama

Birmingham,USA
Professor RoshiniPeiris - John

Section of Epidemiology and Biostatistics Faculty of Medical andHealth Sciences University of Auckland, New Zealand

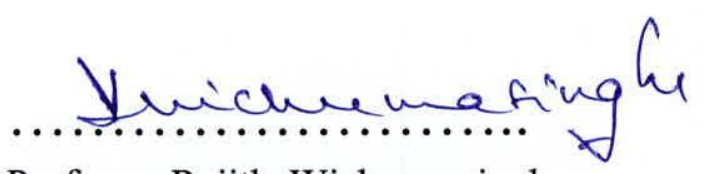

Professor RajithaWickramasinghe Department of Public Health Faculty of Medicine University of Kelaniya 
Dedicated to my parents, my wife Kumudu, my son \& daughter Ashan\&Ashara 


\section{TABLE OF CONTENTS}

TABLE OF CONTENTS i

LIST OF TABLES

LIST OF FIGURES $\quad$ xv

LIST OF ABBREVIATIONS Xvi

$\begin{array}{lc}\text { ACKNOWLEDGEMENTS } & \mathbf{x x}\end{array}$

$\begin{array}{lll}\text { ABSTRACT } & \text { xvii }\end{array}$

1. INTRODUCTION

$\begin{array}{ll}1.1 \text { Objectives } & 7\end{array}$

$\begin{array}{ll}\text { 1.1.1 General objectives } & 7\end{array}$

$\begin{array}{lr}\text { 1.1.2 Specific Objectives } & 7\end{array}$

$\begin{array}{lr}\text { 2. LITERETURE REVIEW } & 8\end{array}$

2.1 Work related musculoskeletal disorders (WRMSD) 9

2.1.1. Definition of WRMSDs 9

$\begin{array}{ll}\text { 2.1.2 History of work related musculoskeletal disorders } & 12\end{array}$

$\begin{array}{ll}\text { 2.1.3 Classification of work related musculoskeletal disorders } & 13\end{array}$

2.1.3.1 Upper limb disorders $\quad 15$

$\begin{array}{ll}\text { 2.1.3.2 Back disorders } & 15\end{array}$

2.1.4 Symptoms of WRMSD 15 
2.1.6.2 Physical risk factors in the working environment

2.1.6.3 Organizational and psychosocial risk factors 
2.2.3.3.2.1 Ergonomic risk factors in hospitals $\quad 42$

2.2.3.4 Relationship between Ergonomics and WMSD 43

2.2.3.5 Nurses' Knowledge Attitudes and Practices related to work ergonomics $\quad 44$

2.3. Low Back pain (LBP)

2.3.1. Definition $\quad 45$

2.3.2 Types of LBP $\quad 46$

$\begin{array}{ll}\text { 2.3.2.1 Chronic LBP } & 47\end{array}$

2.3.3. Anatomy of the back 49

$\begin{array}{lr}\text { 2.3.3.1 Intervertebral disc } & 50\end{array}$

2.3.3.2 Lumbar Spine $\quad 52$

2.3.3.3 Muscles of the back $\quad 54$

2.3.3.4 Ligaments of the Lumbar spine $\quad 57$

$\begin{array}{ll}\text { 2.3.4 Mechanism of LBP } & 58\end{array}$

2.3.5 Epidemiology of the LBP 59

2.3.5.1 Prevalence of LBP among different working populations 61

$\begin{array}{ll}\text { 2.3.5.2 LBP prevalence among nurses } & 61\end{array}$

$\begin{array}{ll}\text { 2.3.6 Risk factors for LBP } & 65\end{array}$

$\begin{array}{ll}\text { 2.3.6.1 Known risk factors } & 65\end{array}$

$\begin{array}{ll}\text { 2.3.6.2 Risk factors LBP for nurses } & 68\end{array}$

$\begin{array}{ll}\text { 2.3.6.3 Risk factors for back Injuries } & 70\end{array}$

$\begin{array}{ll}\text { 2.3.7 Burden of LBP } & 70\end{array}$ 
2.3.8.1 Common strategies for management of LBP 72

2.3.8.2. Evidence based practices for management of LBP 75

2.3.8.3 Education to reduce LBP 77

2.3.8.4. Exercise as a mean to reduce LBP 78

2.3.9 Prevention of LBP $\quad 81$

2.3.9.1 Prevention of in general $\quad 81$

2.3.9.2 Prevention of LBP among nurses $\quad 82$

2.3.10 Measurement Scales for functional outcomes of LBP 84

2.3.10.1 Measuring back pain associated disability $\quad 84$

$\begin{array}{ll}2.3 .10 .1 .1 & \text { Symptom diaries } \\ & 85\end{array}$

2.3.10.1.2 Visual Analogue Scale (VAS) 86

$\begin{array}{ll}\text { 2.3.10.1.3 Quebec Back Pain Disability Scale } & 87\end{array}$

2.3.11 Cross cultural Validation of Health measurement $\quad 88$

2.3.11.1 Testing Validity and reliability of a health outcome measures $\quad 89$

3. METHODOLOGY 92

3.1 Summary of the studies conducted $\quad 92$

3.1.1. Stage 1: Cross sectional analytic study to determine prevalence of 95 musculoskeletal disorders in four occupational groups

3.1.1.1. Study setting $\quad 95$

3.1.1.2. Recruitment of participants $\quad 96$ 
3.1.1.3. Sample size calculation $\quad 96$

3.1.1.4 Data collection $\quad 98$

3.1.1.4.1.Sociodemographic and anthropometric data 102

$\begin{array}{ll}\text { 3.1.1.4.2. Nature of the job task } & 102\end{array}$

$\begin{array}{ll}\text { 3.1.1. } 4.3 \text { Psychosocial variables } & 102\end{array}$

$\begin{array}{ll}\text { 3.1.1.4.4 Musculoskeletal symptoms } & 103\end{array}$

3.1.1.4.5 Personal beliefs about the causes of pain and pain reduction $\quad 104$

3.1.1.4.6 Prevalence of brief symptoms (health problems experienced during 105 past seven days)

$\begin{array}{ll}\text { 3.1.1.4.7 Emotional content } & 105\end{array}$

$\begin{array}{ll}\text { 3.1.4.8 Sick leave taken } & 105\end{array}$

$\begin{array}{ll}\text { 3.1.1.5. Data processing and analysis } & 105\end{array}$

3.1.2 Stage II: Cross sectional survey among NOs 106

$\begin{array}{ll}\text { 3.1.2.1 Study setting } & 106\end{array}$

$\begin{array}{ll}\text { 3.1.2.2 Sample size } & 107\end{array}$

$\begin{array}{ll}\text { 3.1.2.3 Recruitment of participants } & 109\end{array}$

$\begin{array}{ll}\text { 3.1.2.4 Data collection } & 109\end{array}$

$\begin{array}{ll}\text { 3.1.2.4.1 Study instrument } & 111\end{array}$

$\begin{array}{ll}\text { 3.1.2.4.2 Personal demographic characteristics } & 111\end{array}$

3.1.2.4.3 Anatomy of the back $\quad 112$

3.1.2.4.4 Knowledge about work ergonomic principals $\quad 112$ 

version of Quebec back pain disability scale

\section{And Exercise Program (IBDEEP)}

$$
\text { 3.3.2 .1 Experimental design }
$$


3.3.2.2 Integrated Back Discipline Education Intervention

4.1.3 Psychosocial factors in the work place by occupational group 
pain in the past 12 months

4.1.5.1 Mail sorting officers 152

4.1.5.2 Sewing machinists 152

4. 1.5.3 Nursing officers 161

4.1.5.4. Computer operators 161

4.2 Results of Stage 2

4.2.1. Demographic and occupational characteristics of nurses $\quad 170$

4.2.2 Nurses' knowledge on work related ergonomics 172

4.2.3 Nurses' attitudes on work related ergonomics 174

4.2.4 Practices related to work ergonomics among nurses 174

$\begin{array}{lr}4.3 \text { Results of stage 3(a) } & 180\end{array}$

$\begin{array}{lr}\text { 4.3.1 Demographic characteristics of participants } & 180\end{array}$

4.3.2 Correlation between the Sinhala version of QBDS and the 182

Sinhala version of SF-36 health outcome questionnaire

4.4 Result stage 3(b) $\quad 184$

4.4.1 Personal and work characteristics of participants in the 184 intervention and control group

4.4.2 Maintenance of exercise diary by the intervention group and back pain diary by the control group

4.4.3 Differences between drop outs in the intervention group and control group 


\subsubsection{Changes in knowledge attitudes and practices related to work}

\section{ergonomics}

4.4.4.1 Knowledge of attitudes towards and practices related to work

ergonomics in intervention and control groups at pre-test and at post-test

compared to

4.4.4.2 Knowledge of, attitudes towards and practices related to work

Ergonomics in intervention and control groups at post-test compared to pre-test

4.4.4.3 Changes in mean score of knowledge attitudes and practices after

the intervention at post test.

4.4.5 Pain intensity in the VAS and associated disability in SVQBDS in the intervention and control groups at pre-test, six weeks- and three months-after the intervention

4.4.5.1 Changes in pain intensity (measured by VAS) and disability (measured by SVQBSDS) among the intervention and control groups

4.4.5.2 Changes in pain intensity in VAS and disability in SVQBDS

within the groups

4.4.5.3 Changes in mean score of QBDS and VAS after the intervention at post test

\section{DISCUSSIONS}

5.1 Musculoskeletal disorders in different occupational groups

5.1.1 Prevalence of musculoskeletal symptoms and associated factors and associated disability among MSOs

5.1.2 Prevalence of musculoskeletal symptoms and associated factors and 
associated disability among SMs

5.1.3 Prevalence of musculoskeletal symptoms, associated factors and associated 203 disability among NOs

5.1.4 Prevalence of musculoskeletal symptoms and associated factors and associated disability among $\mathrm{COs}$

5.2 Knowledge, attitudes and practices on work ergonomics among nurses

5.3 Validation of Sinhala version of Quebec back pain disability Scale

5.4 Intervention to reduce LBP among nurses

5.4.1 Changes in knowledge attitudes and practices

5.4.2 Effectiveness of the exercises intervention

$\begin{array}{lr}\text { 5.5 Limitations } & 229\end{array}$

6 CONCLUSIONS AND RECOMENDATIONS 231

$\begin{array}{ll}6.1 \text { Conclusion } & 231\end{array}$

6.2 Recommendations 232

7. RFFERENCES

8. APPENDIXES

$\begin{array}{ll}\text { Appendix } 1 & 271\end{array}$

$\begin{array}{lr}\text { Appendix } 2 & 273\end{array}$

$\begin{array}{ll}\text { Appendix } 2.1 & 274\end{array}$

$\begin{array}{ll}\text { Appendix } 2.2 & 276\end{array}$

$\begin{array}{lr}\text { Appendix } 3 & 278\end{array}$

$\begin{array}{lr}\text { Appendix } 4 & 291\end{array}$ 
$\begin{array}{lr}\text { Appendix } 5 & 298\end{array}$

$\begin{array}{ll}\text { Appendix } 6 & 304\end{array}$

$\begin{array}{ll}\text { Appendix } 7 & 312\end{array}$

$\begin{array}{ll}\text { Appendix } 8 & 316\end{array}$

$\begin{array}{lr}\text { Appendix } 9 & 317\end{array}$

$\begin{array}{ll}\text { Appendix } 10 & 318\end{array}$

$\begin{array}{ll}\text { Appendix } 11 & 336\end{array}$

$\begin{array}{ll}\text { Appendix } 12 & 337\end{array}$

$\begin{array}{ll}\text { Appendix } 13 & 349\end{array}$

$\begin{array}{ll}\text { Appendix } 14 & 350\end{array}$

$\begin{array}{ll}\text { Appendix } 15 & 351\end{array}$ 
Table 3.1: Stages of the study 93

Table3.2: Number of nurses recruited according to employment ratio in each $\quad 108$ Hospital

$\begin{array}{ll}\text { Table 3.3: Summary of the data collected } & 110\end{array}$

$\begin{array}{ll}\text { Table 3.3. : Content of the Educational Workshop } & 127\end{array}$

Table 4. 1: Distribution of study population by demographic, anthropometric, and 137 occupational characteristics

Table 4. 2: Work related organizational factors and nature of job tasks/activities in a typical working day by occupational group

Table 4. 3: Selected psychosocial factors in the work place by occupational group $\quad 146$

Table 4.4: Prevalence of musculoskeletal symptoms in the past twelve months by 149 anatomical site and occupational group

Table 4. 5: Prevalence of any musculoskeletal pain in the past month by anatomical site and occupational group

Table 4.6.: Prevalence of disabling pain in the past month by anatomical site and occupational group

Table 4. 7: Association of work related risk factors with the prevalence of low back pain, neck pain and shoulder pain during the past 12 months Among MSO

Table 4.8: Association of work related risk factors with the prevalence of wrist and hand pain, knee pain and elbow pain during the past 12 months Among MSO

Table 4. 9: Association of the work related risk factors with the prevalence of low back pain, neck pain, and shoulder during the past 12 months Among SMs

Table 4.10: Association of the work related risk factors with the prevalence of low back pain, neck pain and shoulder pain during the past 12 months Among SMs

Table 4.11: Association of the work related risk factors with the prevalence of low back pain, neck pain and shoulder pain during the past 12 months Among NOs

Table 4.12: Association of the work related risk factors with the wrist and arm pain, 
knee pain, and elbow pain during the past 12 months among NOs

Table 4.13: Association of the work related risk factors with the low

back pain, neck pain, and shoulder pain during the past 12 months

Among COs

Table 4. 14 : Association of the work related risk factors with the wrist and hand pain, knee pain and elbow pain during the past 12 months Among COs

Table 4.15: Demographic and occupational characteristics of nurses from the four selected hospitals

Table 4.16: Nurses' knowledge on work related ergonomics

Table 4.17: Level of knowledge on different aspects of work ergonomics

among nurses

Table 4.18: Attitudes towards work ergonomics among nurses

Table 4.19: Practices related to work ergonomics among nurses

Table 4.20: Demographic characteristics of study population and scores of QBDS and SF36

Table 4.21: Internal consistency of Sinhala translation of Quebec Back pain Disability

Table 4.22: Personal and work related characteristics in the intervention and

Control groups

Table 4.23: Outcome measures in the Exercises diary maintained by the intervention group and back pain diary maintained by the control group

Table 2.24: Difference of personal characteristics of between drop outs in intervention and control groups

Table 4.25: Knowledge of, attitudes towards, and practices related to, work ergonomics between intervention and control groups in pre- and post-tests

Table 4.26: Knowledge of, attitudes towards, and practices related to, work ergonomics among participants in the intervention and control groups (pre-test and post-test)

Table 4.27: Changes in mean values of knowledge, attitudes and practices scores between intervention and control groups at the post-test after three months 
Table4.28: Score of the SVQBDS and VAS after six weeks and three months

Table4.29: Intensity of LBP and associated disability at baseline and six weeks and three months after of the intervention

Table4.30: Changes in the mean value of SVQBDS and VAS score after six weeks and three months 
Figure 2.1 Organizational structure of the literature review 9

Figure 2.2: Lateral view of the vertebral column illustrating the spinal curvatures $\quad 49$

Figure: 2.3 Features of typical vertebrae A-superior view and B -Lateral view $\quad 50$

Figure: 2.4 A Structure of the Intervertebral disc $\quad 51$

Figure: 2.5 - A cut out portion of a normal disc $\quad 52$

Figure 2.6: Low-back vertebrae: L1, L2, L3, L4, and L5 53

Figure: 2.7 Anteriosuperior view of lumbar vertebrae $\quad 54$

Figure 2.8: Muscles of the back. $\quad 56$

Figure 2.9: Innervations of the intervertebral disc $\quad 57$

Figure 2.10-Ligaments of the Lumbar spine $\quad 58$

Figure 2.11: The process leading to back pain after a back injury 59

Figure 2.12: The relationship of incidence of LBP with physical, psychological and 66 personal factors

$\begin{array}{ll}\text { Figure 3.1 Summary of the data collected for the baseline survey } & 100\end{array}$

$\begin{array}{ll}\text { Figure 3.2: Components of the intervention study } & 122\end{array}$ 


\section{LIST OF ABRIVIATIONS}

$\begin{array}{lll}\text { ABH } & - & \text { Awissawella Base Hospital } \\ \text { AIHA } & - & \text { American Industrial Hygiene Association } \\ \text { ANA } & - & \text { American Nurses' Association } \\ \text { ASCC } & - & \text { Australian Safety and Compensation Council } \\ \text { BLS } & - & \text { Bureau of Labor Statistics } \\ \text { CANS } & - & \text { Complaints of arm neck and/or shoulder } \\ \text { CBSQ } & - & \text { Curtain Back Screening Questionnaire } \\ \text { CIHI } & - & \text { Canadian Institute for Health Information } \\ \text { COAAS } & - & \text { Center on an Aging Society, Georgetown University } \\ \text { CO } & - & \text { Computer Operator } \\ \text { CSTH } & - & \text { Colombo South Teaching Hospital } \\ \text { CLBP } & - & \text { Chronic low back pain } \\ \text { CTD } & - & \text { Cumulative Trauma Disorder } \\ \text { CI } & - & \text { Confidence Interval } \\ \text { CSSD } & - & \text { Central Sterile Supplies Department } \\ \text { DALY } & - & \text { Disability Adjusted Life Years } \\ \text { DPQ } & - & \text { Dallas Pain Questionnaire } \\ \text { DRI } & - & \text { Disability Rating Index } \\ \text { EASHW } & - & \text { European Agency for Safety and Health at Work } \\ \text { EPF } & - & \text { Employee Providence Fund } \\ \text { FEF } & - & \text { Friedrich Ebert Foundation } \\ \text { FSQ } & - & \text { Functional Status Questionnaire; } \\ \text { GP } & - & \text { General Practitioner }\end{array}$




\begin{tabular}{|c|c|c|}
\hline HBH & - & Homagama Base Hospital \\
\hline HESIS & - & Hazard Evaluation System and Information Service \\
\hline HIV & - & Human Immunodeficiency Virus \\
\hline HAS & - & Health and safety Authority \\
\hline HSE & - & Health and Safety Executive \\
\hline IHE & - & Institute of Health Economics \\
\hline IHME & - & Institute for Health Metrics and Evaluation \\
\hline IOF & - & International Osteoporosis Foundation \\
\hline IHME & - & Institute for Health Metrics and Evaluation \\
\hline IEA & - & International Ergonomics Association \\
\hline IHME & - & Institute for Health Metrics and Evaluation \\
\hline IASP & - & International Association for the Study of Pain \\
\hline IAPA & - & Industrial Accident Prevention Association \\
\hline ICD & - & International classification of disease \\
\hline ILO & - & International labour organization \\
\hline JOA & - & Japanese Orthopedic Association \\
\hline LBP & - & Low back pain \\
\hline LBPR & - & Low Back Pain Rating \\
\hline MSD & - & Musculoskeletal disorders \\
\hline MSO & - & Mail Sorting officer \\
\hline NASS & - & North American Spine Society \\
\hline NIOSH & - & National Institute for Occupational Safety and Health \\
\hline NIHCE & - & National Institute for Health and Clinical Excellence \\
\hline NO & - & Nursing officer \\
\hline
\end{tabular}




\begin{tabular}{|c|c|c|}
\hline NHSL & - & National Hospital Sri Lanka \\
\hline NKP & - & Neck Pain \\
\hline ODI & - & Oswestry Disability Index \\
\hline OHCOW & - & Occupational Health Clinic for Ontario Workers Inc. \\
\hline OHSCO & - & Occupational Health and Safety Council of Ontario \\
\hline oos & - & Occupational overuse syndrome \\
\hline OPD & - & Out Patient Department \\
\hline OR & - & Odds Ratios \\
\hline OSHA & - & Occupational Safety and Health Administration \\
\hline QPDS & - & Quebec Back Pain Disability Scale \\
\hline RMDQ & - & Roland-Morris Disability Questionnaire \\
\hline RCT & - & Randomized Control Trial \\
\hline RR & - & Relative Risk \\
\hline RSI & - & Repeated strain injuries \\
\hline SD & - & Standard Deviation \\
\hline SHC & - & Subjective Health Complaints \\
\hline SLMA & - & Sri Lanka Medical Association \\
\hline SIP & - & Sickness Impact Profile \\
\hline SLIIT & - & Sri Lanka Institute of Information Technology \\
\hline SM & - & Sewing Machinist \\
\hline SPSS & - & Statistical Package for the Social Sciences \\
\hline SVQBDS & - & Sinhala Version of Qubece Back Pain Disability Scale \\
\hline ULD & - & Upper Limb Disorders \\
\hline USA & - & United State of America \\
\hline
\end{tabular}


VAS - Visual Analogue Scale

WHO - World Health Organization

WRMSD - $\quad$ Work related musculoskeletal disorders

YLD - - Years Lost due to Disability 


\section{AKNOWLADGEMENT}

- Many people have helped me in the process of making this study a success. The main prerequisites for a doctoral student to succeed are the supervisors. I have heard that a simple decision can change our lives; I feel I have made the best decision to chose professor Roshini John Peiris to be my first immediate supervisor. Her competence, knowledge, patience and friendship were key elements to making my $\mathrm{PhD}$ such an enjoyable experience. From the bottom of my heart I would like to thank you. You are simply the best!

- I acknowledge with great respect Prof.Rajitha Wickramasinghe, Senior Professor Faculty of Medicine University of Kelaniya for being my principal supervisor .He provided me with all the guidance directions and kept me in most inspiring research environments ,scientific meetings and also he played an essential role in fulfilling requirement of this thesis. He is above all the one who has led me through the process of learning how to do research. For his endless patience and valuable time in assisting me with the statistical analysis and design of the main study. I was blessed to have had an opportunity to work with him. I am most grateful to Professor Rajitha Wickramasinhe

- I am gratefully acknowledge Prof..Nalini Sathyakumar, University of Alabama Birmingham, USA. Being a supervisor, she was one of the great contributor to make this study a success. Providing funds for the whole study and also giving me opportunities to attend various national and international research forums and study 
programms she strengthen me from different aspects. I indebted to Prof.Nalini Sathiyakumar

- I am grateful to Prof.S Sivayogan, senior lecturer in Community Medicine, University of Sri Jayewardenapura. Being the internal supervisor during the past three years, he was behind me and guided me all the time when I have problems. His experience and expertise in field of research has been great help for me to complete this study.

- I would like to especially acknowledge Prof.David Coggan, University of South Hampton, UK. He helped me immensely at various stages of this study by guiding and directing with regards to occupational health aspect of this study and also greatly contributed to correcting and publishing my papers.

- I would like to express my warmest gratitude to the official examiners of this thesis

- I would like to specially thanks, Former Dean Professor Jayantha Jayewardena and present Dean Professor Mohan de Silva, Faculty of Medical Sciences and Vice Chancellor Dr NLA Karunarathna University of Sri Jayewardenpura for granting me leave for this study at two stages during the past five years.

- My grateful thanks to former Heads of Department of Medical Education and Health Sciences, Dr Kusuma Ruberu,Prof Deepthi Samarage, Prof. Sherain Fernando and present Head of the Department of Allied Health Sciences Prof. Kamani Samarasinge for their kindness to grant me study leave and all the other support extended during this study. 
- My sincere thanks to Clerical staff of the Faculty of Graduates Studies and Faculty of Medical Sciences for their kind corporation throughout this study

- Special thanks to Prof.Sagarika Ekanayaka, chairperson, Board of Studies, Faculty of Medical Sciences, University of Sri Jayewardenepura for giving me grace period to submit my thesis considering my unpreventable delays.

- I would like to thanks following staff members in the Department of Community Medicine and Physiology for helping me in various way to complete my study including Dr. Gunawardena, Dr Wijesiri, Dr Wathsala Jayasooriya,Dr Chamini Prathapan and Dr Nalinda Silva

- I would like to thanks Miss Sujatha Senevirathna, Former coordinator and other staff members of the BSc Nursing Program for helping me in various ways during this study

- I would like to thanks and Librarian Miss Shirani Dharmawardena for her assistance in literature review.

- I would like to acknowledge all the Directors and Medical Superintendents of following hospitals for giving permission to access nurses and patients for data collection at different stages of this study.

Former Director National Hospital Sri Lanka,Dr.Hector Weerasinghe Former Director Colombo South Teaching Hospital,Dr Anil Jasinghe Dr. Gamage, Director Sri Jayewardenepura General Hospital, Former Medical Superintendent Dr. Karunarathna Samarakoon Base Hospital Homagama

Former Medical Superintendent, Dr. Sumeda Panagoda Base Hospital Avissavella 
Mr.Disanayake, Former Post Master General, Ministry of Postal and

Telecommunication

Mr Sunil, Superintendent, Central Mail Exchange,

Mr Udaya, Public Health Inspector, Boralasgamuwa $\mathrm{MOH}$ area

- Special thanks to following Managers and heads of the departments of private sector institutes for giving me permission to access their employees

Mr.Chandana Perera Managing Director MRC Associated Private Limited Boralasgamuwa

Section manager Mr. Shantha Shanthia Grament Boralassgamuwa Mr Anada Presanna Manager in Information Technology, Huchison Lanka Bambalapitiya

Dr Waidyasekara, Senior Lecturer Sri Lanka Institute of Information Technology

Mr.Manjeewa Silva, software engineer, Verthusa Company, Dematagoda Branch

Mr.Sanjeewa, Section Manager International Financial System

(IFS),Dehiwala

Mr.Kr Sajith Anuranga, Software Engineer, Informatics International Private Limited, Nugegoda

- Chief Special grade nursing officers for facilitating data collection in their Avissavella hospitals

Chief Special grade nursing officers in SLNH

MS. Seetha Perera Chief Special Grade Nursing Officer , National Hospital Sri Lanka 
MS. Gunathilaka and Thilakarathna Colombo South Teaching Hospital

MS Neranjala Saputhanthree Chief Special Grade Nursing Officer Sri

Jayewardenapura General Hospital

MS Chintha, Chief Special Grade Nursing Officer ,Base Hospital

Homagam

MS Melka, Chief Special Grade Nursing Officer Base Hospital Avissawella

- I would like to thanks following Managers and Heads of the Departments of two

- I would like to specially acknowledge following resource persons for the educational intervention program

Dr Latlith Wijerathna Consultant, Rheumatologists National Hospital Sri Lanka

Dr Wajira Palipana, Consultant in Occupational Medicine, Deputy

Commissioner, national Institute of Occupational Health

Dr Sanjeewanee Kurukulasooriya Consultant, Rheumatologists and Senior Lecturer, Faculty of Medicine, University of Kelaniya

Dr .Nishantha Kumarasinghe, Senior Lecture, Department of Anatomy,

Faculty of Medical Sciences, University of Sri Jayewardenepura

Mr. Prasanna Jayathilaka, Psychologist and Professional Counselor, Sri

Lanka Family Planning Association

Mr Rohana Perera, the Principal (Physiotherapist), School of Physiotherapy, Colombo 
Ms Sumana Karunarathna, Chief Physiotherapist, National Hospital Sri

Lanka

- Special thanks to following physiotherapists for participants selection in intervention and control

Mr Variapperuma, Chief Physiotherapist, Colombo South Teaching Hospital

Mr.Chandana, Physiotherapist Sri Jayewardenepura General Hospital

- Special Thanks to Dr Aranjen Karunarathna, Senior lecturer ,Faculty of Medicine ,University of Kelaniya for his guidance at the initial stage of this study

- I would like to thanks following people who gave additional support to the intervention program

President Sujatha Senavirathna, Secretary MS Karunarathna and executive committee members Graduate Nurses" Foundation for their support throughout intervention proramme

Keerthi Wanasekara, the Principal, School of Nursing Colombo for giving auditorium for conducting exercises sessions when hospital venues are not available Research assistants Dr Mahesh, for data collection at the second stage of the study Dr Suwin and Dr.Lathika, coordinators for the ITREOH project, Faculty of Medicine University of Kelaniya

Miss Kalpani Abesinghe and Miss. Muditha Muthukumarana. BSc nursing graduates (demonstrators) for collecting data in the intervention program Miss Prasangi Wijesinghe and Miss Helan Wijerathna, Nursing Officers, National Hospital Colombo for facilitating exercises sessions as trainers 
- I would like to acknowledge all the research participants involved in three stages of the study.

- I want to thank my family for their support and especially my Wife Kumudu, Son Ahan and Daughter Ashara for their assistance, patience and love throughout this study.

- International Training and Research in Environmental and Occupational Health (ITREOH) Program of the University of Alabama at Birmingham (5 D43 TWO5750 from the National Institutes of Health and the Fogarty International Center (NIH-FIC),USA USA is acknowledged for the financial assistance and training during this project .

- Special thanks to ITREOH project, Faculty of Medicine, University of Kelaniya 


\title{
Cultural and Psychosocial Influences on Disability (CUPID) and an intervention to reduce low back pain among nursing officers
}

\section{S.S.P. Warnakulasuriya, Roshini Peiris-John, S.Sivayogan, N.Sathiyakumar, A.R Wikramasinghe}

\begin{abstract}
Work-related musculoskeletal disorders (WRMSDs) are a significant public health problem because of their impact on disability, personal suffering, and absence from work. Increasingly, evidence of work-related MSDs is emerging from developing countries. Most developed countries have to a large extent addressed this, although many developing countries lag behind. In Sri Lanka, musculoskeletal disorders among working populations have not been sufficiently investigated. This study was carried out to assess WRMSD in four selected occupational groups and to evaluate an intervention to reduce LBP among nurses in three stages. The prevalence of WRMSD and its associated factors among mail sorting officers (MSOs), sewing machinists (SMs), nursing officers (NOs) and computer operators (COs) were determined. The study also describes nursing officers' knowledge attitudes and practices related to work ergonomics. The efficacy of the combined educational and exercise intervention in reducing low back pain among nurses was evaluated. The Sinhala version of the Quebec back pain disability scale (QBDS) was validated to measure improvement in disability related to back pain in the evaluation of the intervention programme.

In the first stage, 852 participants were interviewed using a validated questionnaire to ascertain demographic characteristics, MSD symptoms and associated disabilities from four occupational groups including 250 (MSOs), 213 (SMs), 236 (NOs) and 153 (COs). In the second stage, 861 nursing officers were randomly selected from four hospitals including two
\end{abstract}


teaching hospitals and two base hospitals in the Colombo district according to the nurses' ratio in each hospital. A pre-tested self administered questionnaire was administered to the participants after obtaining informed written consent to ascertain the knowledge, attitudes and practices of nursing officers on work related ergonomics.

In order to validate Sinhala version of the QBDS a sample of 140 patients with low back pain (LBP) who attend orthopedic clinics at two teaching hospitals and 140 people with no LBP from among relatives of patients who accompanied the patients to the same clinic were selected. After obtaining informed verbal consent from the participants, the pre-tested Sinhala version of the QBDS and the validated Sinhala version of SF-36 health outcome questionnaire were administered. The SF-36 was administered to correlate the findings with the Sinhala version of the QBDS as a "gold standard" to assess disability related to LBP in Sri Lanka.

In stage 3, a quasi experimental pre-test post-test study was carried out among nurses in two teaching hospitals in Colombo, one with the intervention and one without the intervention. Each arm of the study had 72 nurses with non-specific LBP at the time of the study. The intervention comprised a comprehensive two-day educational workshop on back discipline and correct work techniques and ergonomic principals by a group of experts including a rheumatologist, a physiotherapist, an occupational health \& ergonomics specialist, a psychologist and a professional nurse. The workshop was followed by a series of 30 -minute exercise sessions two days a week for three months. Participants were trained for the exercises and the sessions were supervised by an experienced physiotherapist and two trained staff nurses. The study group was given guidelines to continue exercises at home and a pre- 
designed exercise diary to record pain symptoms and details of home exercises was given to each participant. The control group was given a pre-designed symptom diary with instructions to record back pain symptoms. Both groups recorded the leave taken and visits to doctors, and any medication taken for back pain.

Data analysis was carried out using the Statistical Package for the Social Sciences (SPSS) (Windows Version 16.0 Chicago IL, USA). In stage 1, frequency distributions were obtained and associations tested using the Chi-square test and ANOVA. In stage 2, the sociodemographic profile of the nurses was tabulated. Knowledge of, attitudes towards and practice of, work related ergonomics were assessed using descriptive statistics and were described as percentages. To validate the Sinhala version of QBDS, Pearson correlation coefficients were used to determine the correlation between the QBDS results and the SF-36 variables to determine construct validity of QBDS. The Student's $t$-test was used to determine whether there was a statistically significant difference between scores of back pain disability and quality of life in the study and reference groups. Internal consistency was assessed using Chronbach alpha coefficient. To test the effectiveness of the intervention, Student's $t$-test and paired t- test were used to compare the mean QBDS scores within and between intervention and control groups.

852 employees from four occupational groups (250 Mail Sorting Officers, 213 Sewing Machinists, 236 Nursing Officers and 153 Computer Operators) participated in the study giving a response rate of $86 \%$. LBP was the commonest site of musculoskeletal pain in all occupational groups except COs. Elbow was the least affected pain site in all occupational groups. Neck pain was highest among COs (25\%) but lowest among MSOs. Shoulder pain 
was the commonest WRMSD reported by MSOs (26.8\%) but the lowest reported by NOs $(16 \%)$. NOs reported the highest prevalence of low back pain $(44.6 \%)$ during the past 12 months while COs reported the lowest prevalence of LBP $(21.5 \%)$. The prevalence of wrist and arm pain was low in all four occupational groups ranging from $9.8 \%-13 \%$. The prevalence of knee pain was highest among NOs (29.6\%) and lowest among COs (12.4\%). The prevalence of disabling pain, dominated by LBP, was highest among NOs (22\%) followed by MSOs (18\%) and SMs (14\%). The most disabling pain among COs was neck pain. Disabling shoulder pain was highest among MSOs and lowest among NOs. The prevalence of disabling pain in the wrist and hand was similar in all four occupational groups (7\%-8\%). The prevalence of disabling knee pain was $29.6 \%$ in NOs and $20.8 \%$ in MSOs.

The association between pain symptoms and work related risk factors were investigated separately among the four occupational groups. Adverse beliefs about physical activity was the only significant predictor of wrist and arm pain among MSOs $(\mathrm{OR}=2.4 ; 95 \% \mathrm{CI}=1.1-5.5)$. Low job security among SMs was significantly associated with neck pain in the past 12 months and time pressure to complete tasks was significantly associated with low back pain $(\mathrm{OR}=2.0 ; 95 \% \mathrm{CI}=1.1-3.9)$ and neck pain $(\mathrm{OR}=2.4 ; 95 \% \mathrm{CI}=1.1-5.2)$. Among the nursing officers, time pressure to complete tasks $(\mathrm{OR}=1.9 ; 95 \% \mathrm{CI}=1.0-3.5)$ and lifting more than $25 \mathrm{~kg}(\mathrm{OR}=2.2 ; 95 \% \mathrm{CI}=1.3-3.9)$ during working hours were significantly associated with LBP. Lifting more than $25 \mathrm{~kg}(\mathrm{OR}=2.5 ; 95 \% \mathrm{CI}=1.0-6.0)$ and low job control $(\mathrm{OR}=2.3$; $95 \% \mathrm{CI}=1.0-5.3$ ) were significantly associated with wrist and arm pain among NOs. Among $\mathrm{COs}$, job insecurity was significantly associated with low back pain $(\mathrm{OR}=2.36 ; 95 \% \mathrm{CI}=1.0$ 5.3) and time pressure to complete tasks was significantly associated with neck pain $(\mathrm{OR}=2.6 ; 95 \% \mathrm{CI}=1.1-6.1)$. 
$53 \%$ of nurses had poor knowledge $(<50 \%)$ of work related ergonomics; knowledge was moderate (50 -74\%) in $281(46.6 \%)$ and none had "good" knowledge (>75\%). Most nurses had negative attitudes towards the work related ergonomics. Out of fourteen statements that reflect attitudes related to work ergonomics, only four were marked favourably by the participants. 12 practices related to nursing jobs, assumed as desired practices to work related ergonomics, were included in the questionnaire. The majority reported that they practice five desired practices during normal day shifts. The seven practices not marked by the majority were considered as "undesirable" practices.

The Sinhala version of QBDS showed that the instrument was easy to understand, reliable and a valid condition specific outcome measure of disability related to LBP among the Sinhala speaking population. The outcomes were significantly correlated with the Sinhala version of SF-36 quality of life questionnaire $[\mathrm{r}=-0.75$; $\mathrm{p}<0.05]$ indicating good construct validity. There was also significant internal consistency (Cronbach's alpha coefficient $=$ $0.91)$.

The effectiveness of the exercise intervention progrmme to reduce LBP among nurses was evaluated .A total of 144 nurses participated in the intervention study ( $n=72$ in the intervention group and $n=72$ in the control group). Most nursing officers were aged 31-40 years. The dropout rate in the intervention group was higher (30.5\%) compared to the control group $(16.6 \%)$, though not significantly $(\mathrm{p}=0.074)$. A pre-test before the intervention, and tests after six weeks of the initiation of, during and after three months of, the intervention were carried out. There were significant differences between the groups in knowledge $(p<0.001)$ and attitudes $(p<0.001)$ after 3-months of the intervention; however, there were no differences in practices between the intervention and control groups $(\mathrm{p}=0.111)$. There were 
no significant differences in the VAS $(\mathrm{p}=0.78)$ and SVQBDS $(\mathrm{p}=0.74)$ at pre-test between intervention and control groups. After six weeks of the intervention, there was a significant decrease in the VAS in the intervention group (Mean=32.8, $\mathrm{SD}=16.5$ ) as compared to the control group (mean=43.8, $\mathrm{SD}=13.7$ ). Scores of the SVBDS indicated that disability improved at six weeks in both the intervention (mean=32.5, $\mathrm{SD}=13.8)$ and the control groups (mean=37.9, $\mathrm{SD}=13.6, \mathrm{t}(58)=-2.2, \mathrm{p}=0.029$ ). At the post test at three months after the intervention, there was no significant difference in pain intensity measured by the VAS in the intervention (mean=43.7, $\mathrm{SD}=14.6$ ) and the control groups (mean=43.2, $\mathrm{SD}=14, \mathrm{t}(59)$ $=0.5, \mathrm{p}=0.571)$. Disability scores measured by the SVQBDS also indicated that there was no significant difference in disability scores between the intervention (mean=38.7, $\mathrm{SD}=15.0$ ) and the control groups $($ mean $=37.2, \mathrm{SD}=16.1)\left(\mathrm{t}_{50}=0.4 ; \mathrm{p}=0.635\right)$.

Preventive strategies for work-related musculoskeletal disorders in Sri Lanka should take account of psychological and physical risk factors. Knowledge related to work ergonomics among nurses leading to more positive attitudes work related ergonomics need to be enhanced in training programmes. Hospital related ergonomic risk factors should be mitigated through system-wise work organization for all staff. The Sinhala translation of the QBDS provides is easy to understand, reliable and a valid condition specific outcome measure of disability related to LBP among the Sinhala speaking population. Knowledge of nurses on work-related ergonomics can be significantly improved through educational workshops which should be utilized in professional education of nurses. Further research needs to be done to identify interventions that would reduce LBP among nursing officers. 